\title{
O USO DA INFORMÁTICA E O ENSINO DE MATEMÁTICA NAS ESCOLAS DA REDE PÚBLICA ESTADUAL EM BELÉM
}

\section{Use of in formation technology and the teaching of mathematics in public schools of Belém}

\begin{abstract}
RESUMO
O presente artigo está baseado nas conclusões de nossa dissertação de Mestrado e trata de discutir algumas dificuldades observadas no emprego do computador como auxiliar pedagógico do professor de Matemática da rede pública estadual paraense, refletindo sobre o (des)preparo desse professor ante um processo contextualizado de aprendizagem construtivista baseada em rede de computadores, enquanto aponta propostas para uma concepção transformadora em Educação Matemática, com vistas a melhorar os indicadores de desempenho nessa disciplina, no estado do Pará.
\end{abstract}

Palavras-chaves: informática na educação, educação matemática, escola pública.

\section{ABSTRACT \\ The present article is based on the conclusions of our master degree and treats to argue some difficulties observed in the computer as to assist pedagogical of the professor of Mathematics of the public net state of Pará, reflecting the preparation (or not) of this professor before a contextualization process based on construtivist learning in computer network, while it points proposals with respect to a transforming conception in Mathematical Education, with sights to improve the pointers of performance in this disciplines, in the state of Pará.}

Keywords: Information Technology in Education, Teacher Education, Public School.
Franz Kreüther Pereira ${ }^{I}$ Tadeu Oliver Gonçalves ${ }^{2}$

\section{CÓdIGOS DE MODERNIDADE E SISTEMAS ANTIGOS}

Em 1990, foi criado, no estado do Pará, o Departamento de Informática e Educação-DIED (extinto em 2004), cujo objetivo era "planejar, coordenar, executar e pesquisar a utilização da Informática no processo ensino-aprendizagem" (QUEIROZ 2002, p.29). Cabia-lhe, ainda, desenvolver pesquisas e coordenar o Centro de Informática e Educação - CIED (extinto em 2001). Em 1998, implantou-se o Programa Nacional de Informática na Educação PROINFO, que criou os Núcleos de Informática e Educação - NTE, na capital e no interior do Estado. Os professores que trabalham nesses NTE são pós-graduados (especialização em Informática e Educação) e capacitados para auxiliar as escolas em todas as fases do processo de incorporação das novas tecnologias.

Atualmente, o estado do Pará conta com cerca de 169 laboratórios de Informática em escolas da rede pública estadual, contudo, temos observado que, nesses 16 últimos anos, o incremento em tecnologia Informática com fins pedagógicos nas escolas da rede pública estadual não se converteu em melhorias no processo ensino-aprendizagem em Matemática. Muitas escolas da rede pública estadual paraense dispõem de biblioteca, de laboratório de informática como computadores conectados a Internet, TV, vídeo, antena parabólica e de um laboratório multidisciplinar (kits de Física, Química e Biologia); entretanto, segundo os resultados do Sistema de Avaliação do Ensino Básico-SAEB [fonte:www.inep.gov.br], o

\footnotetext{
${ }^{1}$ Mestre em Ensino de Ciências e Matemáticas pela Universidade Federal do Pará, Brasil(2005), Licenciado em Física, atuando como professor efetivo da Secretaria Executiva de Educação do Estado do Pará.

${ }^{2}$ Doutor em Educação Matemática pela Universidade Estadual de Campinas é docente do Programa de Pós-graduação em Educação em Ciências em Matemática do Núcleo de Apoio ao Desenvolvimento Científico da UFPA. Tem experiência na área de Educação Matemática e seu campo de pesquisa tem ênfase na Formação de Formadores e de Professores de Matemática, atuando principalmente nos seguintes temas: educação matemática, formação de professores, ensinoaprendizagem, história da matemática e ensino da matemática
} 
índice de alunos da rede pública aprovados no Ensino Fundamental caiu de 69,7\%, em 1999, para $68,9 \%$, em 2003. Os aprovados no Ensino Médio subiram um pouco, passando de 73,4\% para $76,2 \%$, em igual período; mas os indicadores do SAEB-2003 também revelam que, em se tratando de competências em Matemática, a situação no estado piorou em ambos os níveis de ensino, e as expectativas criadas com a introdução do computador no ensino-aprendizagem, mesmo fundamentada nos $\mathrm{PCN}$, ainda não atingiram um nível satisfatório.

Nesse cenário, cabem algumas indagações, tais como: essas tecnologias são empregadas nessas escolas há tempo suficiente para promover as mudanças pretendidas? A introdução do computador provocou algum impacto no ensino de Matemática nessas escolas? O professor auxilia o estudante a sistematizar os conhecimentos matemáticos através dos recursos da informática? Os recursos tecnológicos disponíveis nas escolas são satisfatórios e os recursos humanos foram adequadamente preparados? Se sim, o que faltou? Onde ocorreu a falha?

Durante a pesquisa que realizamos para nossa dissertação de mestrado [Pereira, 2005], entrevistamos 19 professores de Matemática da rede pública estadual do Pará, lotados em 9 grandes escolas da capital paraense, e nossa pesquisa revelou que os professores não exploravam satisfatoriamente, e nem de forma adequada, os recursos computacionais disponíveis na sala de informática das escolas onde trabalhavam. Comprovou, ainda, que a maioria dos professores entrevistados não sabia empregar os recursos da informática para elaborar atividades de ensino; não buscava novidades sobre sua atividade profissional na Internet; não se engajava em grupos/listas de discussão sobre Matemática; não procurava conhecer softwares para uso na disciplina e nem sequer reservava espaço em seu planejamento para algumas aulas nesse ambiente computacional.

A análise desses dados convergiu para o fato de que, enquanto faltava-lhes a necessária segurança didático-pedagógica para manusear as tecnologias da informação e comunicação baseada em rede de computadores, sobrava receio de ensinar utilizando essa novidade tecnológica. A pesquisa apontou para uma situação singular: apesar dos diversos cursos sobre o uso da informática na educação, ministrados para professores e técnicos pedagógicos pela equipe do NTE, e apesar de a escola contar com um laboratório de Informática, o ensino de Matemática na rede pública estadual paraense continua conteudista. E, mais, revelou que os professores apresentaram certa resistência ao uso pedagógico do computador, transformando-se dessa forma em um obstáculo maior que a falta de material e de formação continuada.

Os fatores que identificamos como influenciadores nessa atitude de resistência, apontam para a manutenção do status quo que estabelece a prática conservadora e comodista. Em verdade, há um enorme contingente de professores de Matemática que ainda não se apropriou das ferramentas computacionais, ou resistem a utilizá-las em sua atuação pedagógica, por não se sentirem seguros ou por medo de entrar na "zona de risco" [Penteado 2004, p. 284].

Diversas razões foram apontadas pelos professores entrevistados para explicar as razões para não utilizarem o ambiente computacional da escola em atividades pedagógicas. Quase todas incidiam sobre as políticas públicas para esse setor (ou a falta delas) e as ações de descontinuidade de uma gestão para outra. Também alegaram, como impedimento ao uso desse espaço, encontrarem o laboratório fechado por falta de pessoal ou por defeito nas máquinas, e/ou falta de softwares específicos para a disciplina. No reverso da moeda, todos os sujeitos da pesquisa foram unânimes em afirmar que o computador pode ser um auxiliar valioso para dinamizar suas aulas; que "é um bom recurso que serve como alternativa para que o professor não fique somente preso em aulas expositivas" (Professor 09); que "traz um novo olhar ao ensino de Matemática" (Professor 04) e que "...você produz mais com aluno, com aquele conteúdo, com aquela atividade, do que ainda você está em sala de aula tentando colocar fórmulas, colocar os conceitos básicos" (Prof. Maria - Entrevista em 20/12/2004).

Segundo Borba e Penteado (2003, p.89), a entrada tecnologia Informática na escola está 
condicionada à atitude do professor e às suas reflexões sobre as mudanças provocadas pela presença das novas mídias nos coletivos pensantes. Se não houver espaço para sólidas reflexões, "eles tenderão a não utilizar essas mídias, ou a utilizá-las de maneira superficial". Corroborando essas considerações, algumas pesquisas [Cacian 2001 e Ferreira 2004, apud Silva 2005, p.21] apontam para o fato que os profissionais ativos da educação sentem um desconforto quando imersos nessa conjuntura em que necessitam - ou são impelidos a modificar seus métodos e técnicas de ensino e incorporar o 'novo' em sua vida profissional.

Outro fator que devemos levar em consideração para estabelecer um perfil mais fiel da situação é que os professores de Matemática sob investigação foram formados pelas principais universidades locais (UFPA, UEPA e UNAMA) e, considerando que a primeira é a Academia mais antiga, a mais importante e a de maior participação na área da licenciatura, acreditamos que não podemos isentá-la de sua parcela de responsabilidade nesse processo, "já que historicamente a própria universidade foi, e continua sendo, responsável pela formação inicial dos seus formadores de professores e, com raríssimas exceções, os professores do departamento foram formados pela própria UFPA" [Gonçalves 2000, p.15].

Queremos dizer que a formação de professores (não somente em Matemática), conforme se dá atualmente na Universidade Federal do Pará, está longe de contemplar a inserção da tecnologia informática como ferramenta pedagógica dos futuros graduados. Assim, enquanto o lócus por excelência na formação de professores de Matemática não consegue prepará-los para o enfrentamento de situações pedagógicas e cognitivas, mediadas e/ou construídas pelas TIC numa perspectiva investigativa e reflexiva, urge que a SEDUC como o órgão estadual competente, desenvolva políticas efetivas para transformar os indicadores que apresentamos em dados positivos. Tais ações passam, obrigatória e necessariamente, por dois eixos: a presença cada vez mais fortalecida, dinâmica, dos NTE e cursos de formação continuada. O primeiro está imbricado com o segundo e assim devem permanecer, enquanto as Universidades não conseguirem preparar esses profissionais para serem atores e coadjuvantes nesse novo paradigma educacional, nessa ecologia do saber [Almeida e Júnior 2002, p.93].

Tendo em vista que mais de $63 \%$ dos professores pesquisados trabalha na mesma escola desde que ela inaugurou seu laboratório, entendemos que o número reduzido de vezes que os professores de Matemática informaram ter utilizado os computadores em atividades de ensino (em média uma vez por ano!) não configura, efetivamente, como utilização da informática como metodologia auxiliar em suas aulas. Caracteriza, em nossa opinião, uma tímida tentativa de aproximação entre o professor e a máquina. Podemos interpretá-la como os primeiros passos para alcançar um objetivo distante, ainda que o número de caminhantes seja praticamente insignificante ante o universo dos que se limitam à posição de observadores.

Considerando-se que as primeiras iniciativas de se estabelecer melhorias na educação pública paraense com o suporte da Informática aconteceram há mais de década e meia, e que o impacto das ferramentas computacionais nas práticas cotidianas dos professores não tem sido tão efetivo quanto esperado, acreditamos que o impacto epistemológico que confere segurança à transposição didática dos conteúdos matemáticos para o contexto computacional ainda está num processo de amadurecimento. Por outro lado, entendemos que esse mesmo espaço de tempo já deveria ter sido suficiente para que os professores desenvolvessem uma cultura de uso dessa tecnologia em suas aulas ou, pelo menos, terem tido a consciência da presença dessa tecnologia e estabelecido estratégias para seu uso.

É fato que ante a informática "toda a escola deve ter uma nova postura metodológica difícil de implementar, pois exige a alteração de hábitos de ensino há muito consolidados" (PCN.1999, p.99), mas ao se implantar um programa da magnitude desse que discutimos (a informática na educação), é necessário consolidar as políticas públicas criadas para atendê-lo, nos três níveis de poder, e torná-las ativas em cada um desses níveis. Assim, é urgente o desenvolvimento de novas abordagens 
pedagógicas relacionadas a designs de ambientes de aprendizagem colaborativa "em que a tecnologia relacionada a aspectos culturais, sociais e axiológicos favoreça a presença de elos de conexão entre os conceitos explorados" [Muskulin 2003, p.221-2].

Estudos ligados ao uso do computador no processo ensino-aprendizagem têm levado um número cada vez maior de pesquisadores, professores, gestores, políticos, além de desenvolvedores de softwares, a considerar esse o grande transformador da Educação no novo milênio. Todavia, os estudos também apontam para a necessidade de políticas de concretização de tais propostas aliadas à conscientização de professores (de Matemática) e gestores do setor educacional, para o uso das TIC de maneira a melhorar os atuais indicadores do SAEB, ENEM e PISA, mas quando se trata da implantação de políticas para a Educação pública comete-se dois erros comuns, o primeiro é acreditar que existem formas baratas, econômicas, de se obter uma educação de qualidade; o segundo é acreditar que a introdução de novas tecnologias no cotidiano escolar, ainda que precedida de cursos de "capacitação" para os profissionais envolvidos, é capaz de provocar a natural aceitação/incorporação dessas novas ferramentas à práxis pedagógica, com reflexos na melhoria do ensino e o ansiado salto no padrão de qualidade. Nessa ótica, a tecnologia Informática serviria como a ponta seca do compasso, isto é, como ponto de apoio para uma ação pedagógica mais eficiente da/na escola. Chamamos a isso de "raciocínio do compasso", que, em síntese, significa acreditar que, uma vez que o sujeito possui um compasso e sabe para que serve, é impossível considerá-lo capaz de traçar um círculo imperfeito.

\section{REFERÊNCIAS}

ALMEIDA, Fernando J., Júnior, Fernando M. F. (2000) ProInfo: projetos e ambientes inovadores. Brasília-DF, MEC/SEED.

BORBA, Marcelo C., Penteado, Miriam G. (2003) Informática e Educação Matemática. B. Horizonte, Autêntica. $3^{\mathrm{a}}$ ed.

CAPRA, F. (1986) O Ponto de Mutação. São Paulo, Cultrix.

FAGUNDES, Léa da C. Disponível em http://www.midiativa.org.br/index.php/educado res/content/view/full/1053/ (acessada em 03/10/04).

FIORENTINI, D. (2003) Formação de Professores de Matemática: explorando novos caminhos com outros olhares (Org.). Campinas, Mercado das Letras.

GONÇALVES, Tadeu O. (2000) Formação e Desenvolvimento profissional de formadores de professores: o caso dos professores de matemática da UFPa. Campinas, SP. (Tese)

MEC. (1999) Parâmetros Curriculares Nacionais-Ensino Médio. Brasília, MEC Secretaria de Educação Média e Tecnológica.

MORAES, Ma . C. (2002) O Paradigma educacional emergente. Campinas, Papirus. $8^{\mathrm{a}}$ ed.

MUSKULIN, R. (2003) As possibilidades didático-pedagógicas de ambientes computacionais na formação colaborativa de professores de Matemática. In: Fiorentini, D. (org.). Formação de Professores de Matemática: explorando novos caminhos com outros olhares. Mercado das Letras. Campinas, São Paulo.

PENTEADO, Miriam G. (2004.) Redes de Trabalho: expansão das possibilidades da informática na Educação Matemática da escola básica. In: Bicudo, M. A. Viggiani; Borba, Marcelo C. (Orgs) Educação Matemática: pesquisa em movimento. São Paulo, Cortez.

PEREIRA, F. Kreüther. (2005) Código de modernidade e sistemas antigos: a propósito do uso da informática pelos professores de Matemática da rede pública estadual em Belém. UFPA, Pará.

QUEIROZ, Izabel C. Avaliação do Projeto ProInfo através da sua estrutura operacional: estudo de caso do NTE/SEDUC-Belém. (Dissert). UFSC, 2002.

SILVA, J. Carlo. Prática colaborativa na formação de professores: a informática nas aulas de Matemática no cotidiano da escola. (Dissert.), . Uberlândia: UFU, 2005. 